\title{
Monopolar Cell Axons in the First Optic Neuropil of the Housefly, Musca domestica L., Undergo Daily Fluctuations in Diameter That Have a Circadian Basis
}

\author{
E. Pyza a and I. A. Meinertzhagen \\ Neuroscience Institute, Life Sciences Centre, Dalhousie University, Halifax, Nova Scotia, Canada B3H 4J1
}

\begin{abstract}
Two types of monopolar cell interneurons, each with a single representative in every unit cartridge of the first optic neuropil, or lamina, of the housefly's optic lobe, have axons that undergo cyclical changes in diameter. The axons are largest during the beginning of day in a normal LD light cycle and smallest during the middle of the night, changes that were however signiflcant only for one of the cells (L2). The axon cross-sectional area and its cyclical change for both $\mathrm{L} 1$ and L2 were both larger in the proximal lamina. The changes are not a simple consequence of relative osmotic change. Dehydration paradoxically increases axon size, and also fails to alter the day/night rhythm of axon size changes. Under conditions of constant darkness, both axons decrease in size, and one of the cells (L2) retains its cyclical size changes, being larger in the subjective day than in the subjective night. Under conditions of constant light, both axons increase in size, and L2 again shows a cyclical size change, just as under conditions of constant darkness. These changes seen under constant conditions are, by definition, circadian in origin. The effects of exposure to light or darkness can partially reset these circadian changes. One extra hour of light during the day increases the size of L1 and L2, whereas $1 \mathrm{hr}$ of extra dark during the night does not decrease their size. It takes $13 \mathrm{hr}$ of light to reverse the rhythm in size. The mechanism for all these changes is unclear but may involve ionic fluxes, possibly that are secondary to osmotic shifts and probably that involve at least two independent processes.

[Key words: axon size, lamina ganglionaris, neuronal plasticity, dehydration, ionic flux, optic lobe]
\end{abstract}

The visual systems of all animals respond to the natural cycle of day and night, resulting in daily oscillations in the function and sensitivity of the eye. Some of these oscillations, so-called circadian rhythms, are also maintained in constant darkness. Under such rhythms, the function of the eye is regulated endogenously so that the visual system not only responds directly to light but also anticipates the changes in light conditions that

\footnotetext{
Received Dec. 2, 1993; revised June 10, 1994; accepted June 23, 1994

This work was supported by NSERC Grants A 0065 (to I.A.M.) and ISE 0150459 (to E.P.), and by NIH Grant EY-03592 (to I.A.M.). Funding for this research was also provided by the Neural Regeneration and Functional Recovery Network, one of 15 Networks of Centres of Excellence supported by the Government of Canada. We thank Ms. Hilary Bennett for many detailed morphometric measurements.

Correspondence should be addressed to I. A. Meinertzhagen, Life Sciences Centre, Dalhousie University, Halifax, Nova Scotia, Canada B3H 4J1.

a Permanent address: Zoological Museum, Institute of Zoology, Jagiellonian University, Ingardena 6, 30-060 Kraków, Poland.

Copyright (C) 1995 Society for Neuroscience $0270-6474 / 95 / 150407-12 \$ 05.00 / 0$
}

occur during a daily cycle. In the eyes of many vertebrate and invertebrate animals, photoreceptors exhibit day/night and circadian rhythms in both sensitivity and many physiological processes (Barlow et al., 1989; Remé et al., 1991). For example, a circadian rhythm has been recorded in the electroretinograms (ERGs) of insects (Wills et al., 1985) and mammals (White and Hock, 1992). As part of their circadian repertoire, vertebrate photoreceptors shed outer segment disks, and synthesize dopamine and melatonin in a daily cycle (Remé et al., 1991), while in invertebrates, the size of the rhabdom, and the turnover of photosensitive membrane and visual pigment all show day/ night and circadian oscillations (Blest, 1988; Barlow et al., 1989).

In higher Diptera, the size of rhabdomeres and the turnover of photosensitive membrane do not oscillate during the day and night (Williams, 1982), as in other arthropods (Blest, 1988). Both processes are continuous, however, and in Drosophila the turnover of visual pigment is under circadian control (Stark et al., 1988). Thus, the function of photoreceptors in Diptera is also controlled by a circadian mechanism, even if this is not structurally obvious. Moreover, a circadian rhythm exists in the terminals of the photoreceptors in the first optic neuropil, or lamina, of the fly's optic lobe, as revealed by the frequency of synaptic profiles. These changes are compatible with the control of circadian function amongst the photoreceptors of higher Diptera being modulated through transmission in the lamina (Pyza and Meinertzhagen, 1991, 1993).

In the lamina, six photoreceptors, R1-R6, from the eight in each ommatidium of the compound eye, form terminals that innervate a fixed cluster of interneurons so as to constitute a module or cartridge (Trujillo-Cenóz, 1965; Braitenberg, 1967). Two other photoreceptors, R7 and R8, bypass the lamina and terminate in the second optic neuropil, or medulla (TrujilloCenóz, 1965; Boschek, 1971). In each lamina cartridge, the terminals of R1-R6 contact two large lamina cells, the monopolar cells L1 and L2, upon which in Musca they each form about 200 afferent tetrad synapses (Burkhardt and Braitenberg, 1976; Nicol and Meinertzhagen, 1982). In turn, L2 feeds back synaptic input upon the receptor terminals (Strausfeld and Campos-Ortcga, 1977). The numbers of both tetrad and feedback synapses depend upon the light conditions under which flies are reared (Kral and Meinertzhagen, 1989) or held (Rybak and Meinertzhagen, 1990, unpublished observations), and oscillate during the day and night (Pyza and Meinertzhagen, 1993). This rhythm in the feedback synapses is also circadian (Pyza and Meinertzhagen, 1993).

A circadian rhythm in the number of feedback synapses formed by $\mathbf{L} 2$ in the lamina suggests that the function of this monopolar 


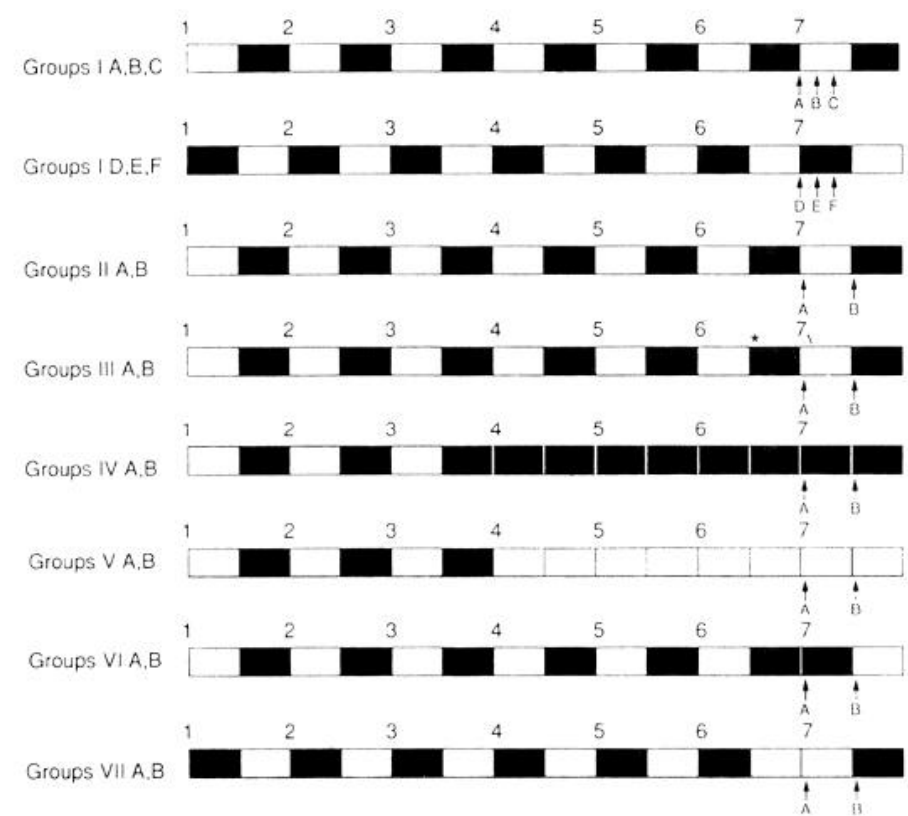

Figure 1. Summary of experimental conditions. Flies are exposed either to light or dark (open and solid portions of bar, respectively). Before being fixed during their 7 th day postemergence, flies received visual experience designed to test whether the axonal calibers of L1 and L2 undergo a daily rhythm (Groups IIA, IIB); the waveform of that rhythm (Groups $I A-I F$ ); the effect of water deprivation on this rhythm (Groups $I I I A, I I I B)$; the presence of a circadian rhythm (Groups $I V, V)$; the resetting of the rhythm (Groups VI, VII). Water deprivation commences $12 \mathrm{hr}$ prior to sampling in Group III (asterisk, Group IIIA; triangle, Group IIIB).

cell might be regulated by a circadian mechanism or even that L2 itself might be a component of an optic lobe circadian system, one that regulates in turn the function of photoreceptors. To address this question further, we sought other day/night and circadian rhythms among monopolar cells. During the process of this search, we examined the sizes of the lamina axons of L1 and L2, which both receive identical synaptic input from R1R6 (Nicol and Meinertzhagen, 1982). These revealed an unsuspected rhythm when examined under the normal cycle of day and night (LD), as well as under either constant darkness (DD) or continuous light (LL). A preliminary report has appeared (Pyza and Meinertzhagen, 1992).

\section{Materials and Methods}

Animals. The housefly (Musca domestica L.) was reared under laboratory conditions at a temperature of $23^{\circ} \mathrm{C} \pm 1{ }^{\circ} \mathrm{C}$, in either LD 12:12 $(12 \mathrm{hr}$ light/12 hr dark) or in a reversed light regimen DL 12:12 (12 hr dark/12 hr light). Lights came on at 09:00 hr in LD and at 21:00 hr in DL. The reversed light DL regimen allowed us to carry out experiments during the day on flies that were in their subjective night. During the night, flies were not in complete darkness but were illuminated by a $\operatorname{dim} 10 \mathrm{~W}$ incandescent red bulb at a distance of $2 \mathrm{~m}$. Details are given in Pyza and Meinertzhagen (1993).

Experimental conditions. After emergence, male or female experimental flies were kept under one of the following seven light regimes (Fig. 1) before being fixed for light microscopy.

Flies from group I (males) were held for $6 \mathrm{~d}$ under either LD or DL conditions and were then fixed on the next day at $4 \mathrm{hr}$ intervals, at 09 : 00, 13:00, 17:00 hr (groups IA, B, C, respectively). For DL reared flies, fixation during the night of DL gave night conditions at times corresponding to 21:00, 01:00, and 05:00 hr for LD flies (groups ID, E, F, respectively).

Flies from group II (females) were held for $6 \mathrm{~d}$ in LD and then fixed on the 7 th day at either 10:00 hr (group IIA) or 22:00 hr (group IIB).
Flies from group III (males) were held for $6 \mathrm{~d}$ in LD and fixed on the 7th day at either 10:00 $\mathrm{hr}$ (group IIIA) or 22:00 $\mathrm{hr}$ (group IIIB), thus receiving the same treatment as groups IIA and IIB, but were water deprived for $12 \mathrm{hr}$ before fixation.

Flies from group IV (females) were held for $3 \mathrm{~d}$ in LD, then $3 \mathrm{~d}$ in DD, and were finally fixed on the 7th day postemergence, at either 10 : 00 (group IVA) or at 22:00 $\mathrm{hr}$ (group IVB).

Flies from group $\mathrm{V}$ (males) were held for $3 \mathrm{~d}$ in $\mathrm{LD}$, then $3 \mathrm{~d}$ in $\mathrm{LL}$, and were finally fixed on the 7 th day at either 10:00 (group VA) or 22: $00 \mathrm{hr}$ (group VB).

Group VI (males) were held for $6 \mathrm{~d}$ in LD, transferred to reversed light DL conditions on the 7th day, and then fixed at either 10:00h during the new night (group VIA) or at 22:00 hr of the new day (group VIB) in DL.

Flies from group VII (males) were held for $6 \mathrm{~d}$ in DL, transferred to LD on the 7th day, and then fixed at either 10:00 $\mathrm{hr}$ (group VIIA) during the new day or at 22:00 hr (group VIIB) during the new night in LD.

Light microscopy. Fly heads were fixed using a cacodylate buffered glutaraldehyde-paraformaldehyde primary fixative, followed by osmication, and prepared for semithin sectioning. Flies from the night or from constant darkness were dissected and fixed under dim red light, all as described previously (Pyza and Meinertzhagen, 1993). Tangential sections of the lamina were cut to obtain cross-sections of the cartridges at a proximal depth, close to the external chiasma, the fiber tract extending between the lamina and the medulla. Sections were cut at $1 \mu \mathrm{m}$ thickness, collected and stained with $1 \%$ toluidine blue, and then viewed and photographed with a Zeiss Photomikroskop II using a 63/1.4 planapochromat objective. The curvature of the lamina means that sections containing a portion of the chiasma at their center cut lamina cartridges at progressively more distal levels towards the section's edges (Fig. 2A) (Kral and Meinertzhagen, 1989). 35mm negatives of those cartridge cross-sections that were located on both sides of the circular profile of the chiasma, along the dorsoventral axis of the eye, were enlarged to a final magnification of 4400 using a microfilm reader (Zeiss Jena, Dokumator DL2) and the profiles of L1 and L2 were drawn. These profiles were then traced and their sizes calculated using a computer morphometric system. The cross-sectional area, perimeter length, and maximum diameter of the axons of L1 and L2 in cross-section were measured at five depths (1-5) of the lamina (Fig. $2 B$ ). Differences between experimental groups were similar in all the morphometric parameters calculated, so that only the measured cross-sectional areas of L1 and $\mathrm{L} 2$ axons are presented. The length of $\mathrm{L} 1$ and $\mathrm{L} 2$ axons were also measured from longitudinal sections of the lamina.

Statistical analyses. The cross-sectional areas of L1 and L2 axons measured at different times of the day in all experimental conditions were calculated as the mean of $20-40$ cells at each of the five depths in the lamina of every fly examined. At least three flies were examined in each experimental group, so that at least 60 cells were sampled for each depth. In groups IIA, IIB, IVA, and IVB we examined more flies (seven, six, seven, and eight individuals, respectively), because in these groups we also wished to compare differences that occur between individuals within a group with the differences that existed between experimental groups. Differences between groups were calculated from the means of individuals within a group. For all tests the one-factor analysis (ANOVA) was used, followed by the Scheffe $F$ test.

\section{Results}

In all experimental groups, the cross-sectional areas of $\mathrm{L} 1$ and L2 axons were largest at the most proximal level of the lamina (level 1 ) and tapered gradually toward the distal level (level 5). The axon of L2 was larger than that of L1 (Figs. 3, 4), especially at level 1 . At levels 2 and 3 , the difference was smaller while at levels 4 and 5 the areas of both axons' cross-sections were similar, or L1 was even larger than L2. These results may be seen by comparing $A$ and $B$ in each of Figures 5-11, and confirm the earlier findings of Braitenberg and Hauser-Holschuh (1972) for the same regions of the lamina.

\section{L1 and L2 axon sizes in day/night conditions}

The cross-sectional areas of L1 and L2 axons were measured during the day and night. This was done in males (groups IA- 

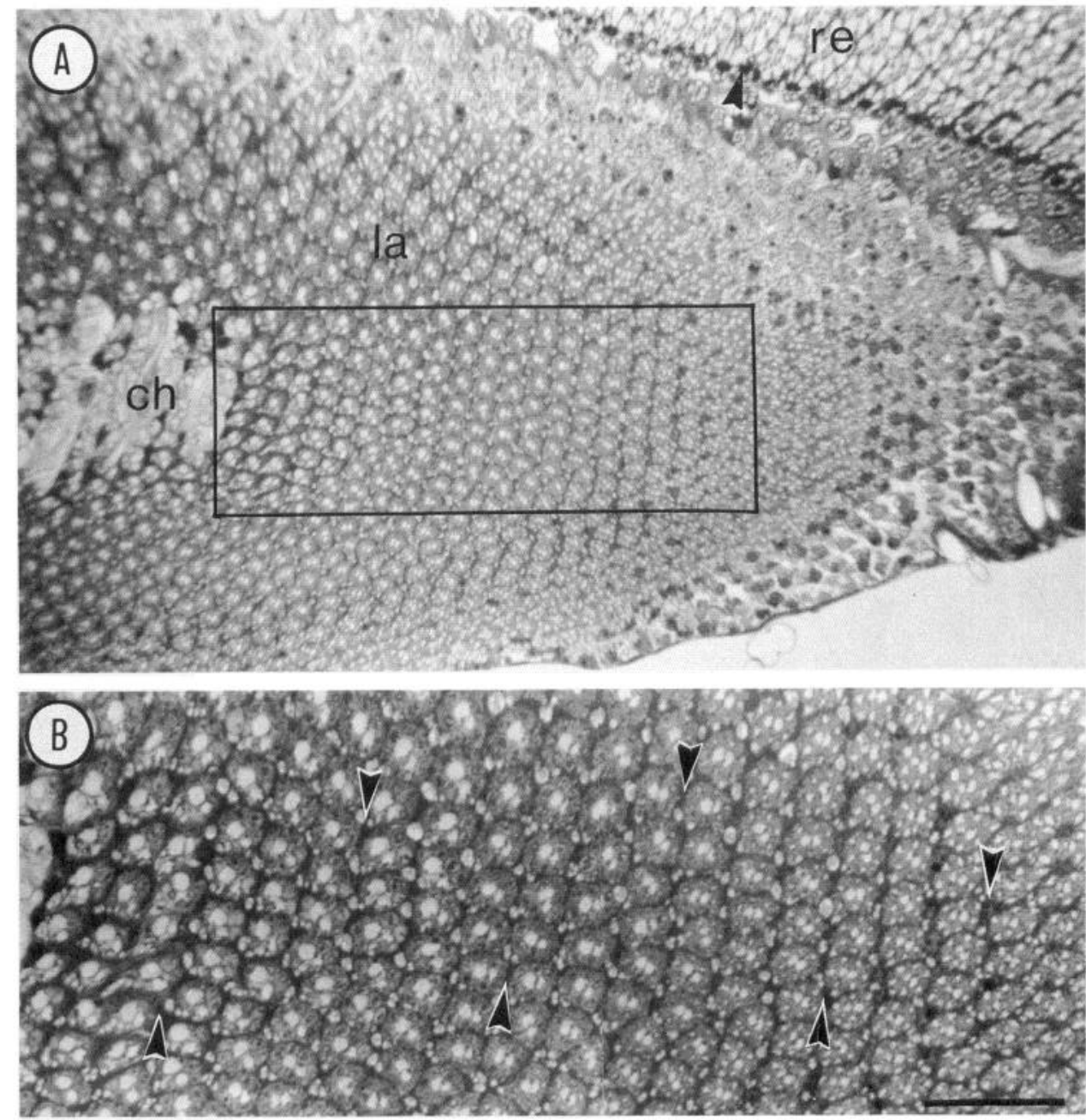

Figure 2. Monopolar cell profiles in the lamina. $A$, Semithin section of the optic lobe, $1 \mu \mathrm{m}$ thick, showing the lamina neuropil $(l a)$ at a proximal depth. Because of the curvature of the eye the central region of the section is cut at a deeper level and contains a portion of the chiasma $(c h)$, while the edge cuts the overlying retina $(r e)$, separated from the optic lobe by the basement membrane (arrowhead). The right of the figure points in a ventral direction. $B, A$ dorsoventrally orientated transect, outlined in $A$, drawn through a row of transversely sectioned cartridges and divided into five regions (levels $1-5$ ), each corresponding to a particular depth at which the cross-sectioned areas of the axons of L1 and L2 were measured. Magnification, $660 \times$; scale bar, $25 \mu \mathrm{m}$.
F) at 4 hrintervals, and at the beginning of day and the beginning of night in both females (groups IIA, B), and after water deprivation in males (groups IIIA, B).

In males, the sizes of the axons of L1 and L2 from flies fixed at $4 \mathrm{hr}$ intervals were measured for alterations in their crosssectional areas during the course of a $24 \mathrm{hr}$ cycle.

L2 was largest at 09:00 $\mathrm{hr}$ (group IA, 14.5 $\pm 3.70 \mu \mathrm{m}^{2} \mathrm{SD}$ at level $1 ; 3.0 \pm 0.84 \mu \mathrm{m}^{2} \mathrm{SD}$ at level 5). Compared with the beginning of day, L2 in male flies decreased an average of 20\% in cross-sectional area in the middle of day (group IB), whereas at the end of day (group IC) and at the beginning of night (group ID) it remained similar to the area during the middle of day (Fig. 5A). L2's axon was smallest $\left(6.4 \pm 2.20 \mu \mathrm{m}^{2} \mathrm{SD}\right.$ at level $1 ; 1.8 \pm 0.92 \mu \mathrm{m}^{2} \mathrm{SD}$ at level 5) at 01:00 $\mathrm{hr}$ (group IE), and the difference in mean cross-sectional area between groups IA and IE was statistically significant $(p=0.02)$. At the beginning of day (group IA), L2 was larger by between $56 \%$ (at level 1 ) and $39 \%$ (at level 5) than at the middle of night (group IE). At 05:00 hr (group IF) L2 increased slightly compared with its size at 01:00 hr, but this difference was not statistically significant.

$\mathrm{L1}$ in males was also largest at 09:00 $\mathrm{hr}$ (group IA, $7.3 \pm 2.30$ $\mu \mathrm{m}^{2} \mathrm{SD}$ at level $l ; 3.5 \pm 0.76 \mu \mathrm{m}^{2} \mathrm{SD}$ at level 5$)$. In the middle of the day (group IB), axon size decreased, increasing again at the end of day (group IC) and at the beginning of night (group ID). These differences were not statistically significant. In the middle of night, at 01:00 hr, the cross-sectional area of L1 decreased $26 \%$ to its minimum (becoming $3.4 \pm 1.34 \mu \mathrm{m}^{2} \mathrm{SD}$ at level $1 ; 2.1 \pm 0.75 \mu \mathrm{m}^{2} \mathrm{SD}$ at level 5 ); at 05:00 $\mathrm{hr}$ its size was unchanged, an average $45 \%$ smaller than at 09:00 $\mathrm{hr}$ (Fig. $5 B$ ). Although the difference in the sizes of $\mathrm{Ll}$ at the beginning of day and at the end of night was significant for all five separate depth levels in the lamina $(p<0.05)$, there was no statistically significant difference in the size of $\mathrm{Ll}$ for the mean of the five cross-sectional areas.

We did not extend observation of axon size into a second 24 hr cycle, but if at 09:00 hr in a second cycle cell size were the same as at 09:00 $\mathrm{hr}$ in the first (group IA), the greatest change in cell size would occur in the hours between 01:00 hr and 09: $00 \mathrm{hr}$. That change would be most visible for a $24 \mathrm{hr}$ cycle starting at 17:00 $\mathrm{hr}$ or 21:00 hr.

The axons of L1 and L2 were also measured in females, to examine if their size also changed, as in males. This examination was carried out at the beginning of day and night, but $1 \mathrm{hr}$ later (10:00 and 22:00, respectively) than in the males in group I above.

L2 was larger at $10: 00 \mathrm{hr}\left(14.2 \pm 3.91 \mu \mathrm{m}^{2}\right.$ SD at level $1 ; 3.3$ $\pm 1.04 \mu \mathrm{m}^{2} \mathrm{SD}$ at level 5) than at $22: 00 \mathrm{hr}\left(8.4 \pm 2.07 \mu \mathrm{m}^{2} \mathrm{SD}\right.$ at level $1 ; 2.5 \pm 0.68 \mu \mathrm{m}^{2} \mathrm{SD}$ at level 5) (Figs. $3 A, B, 6 A$ ). This difference was seen at all five lamina depths (Fig. $6 A$ ). The difference was $41 \%$ at level 1 , decreasing to $23 \%$ at level 5 , was 

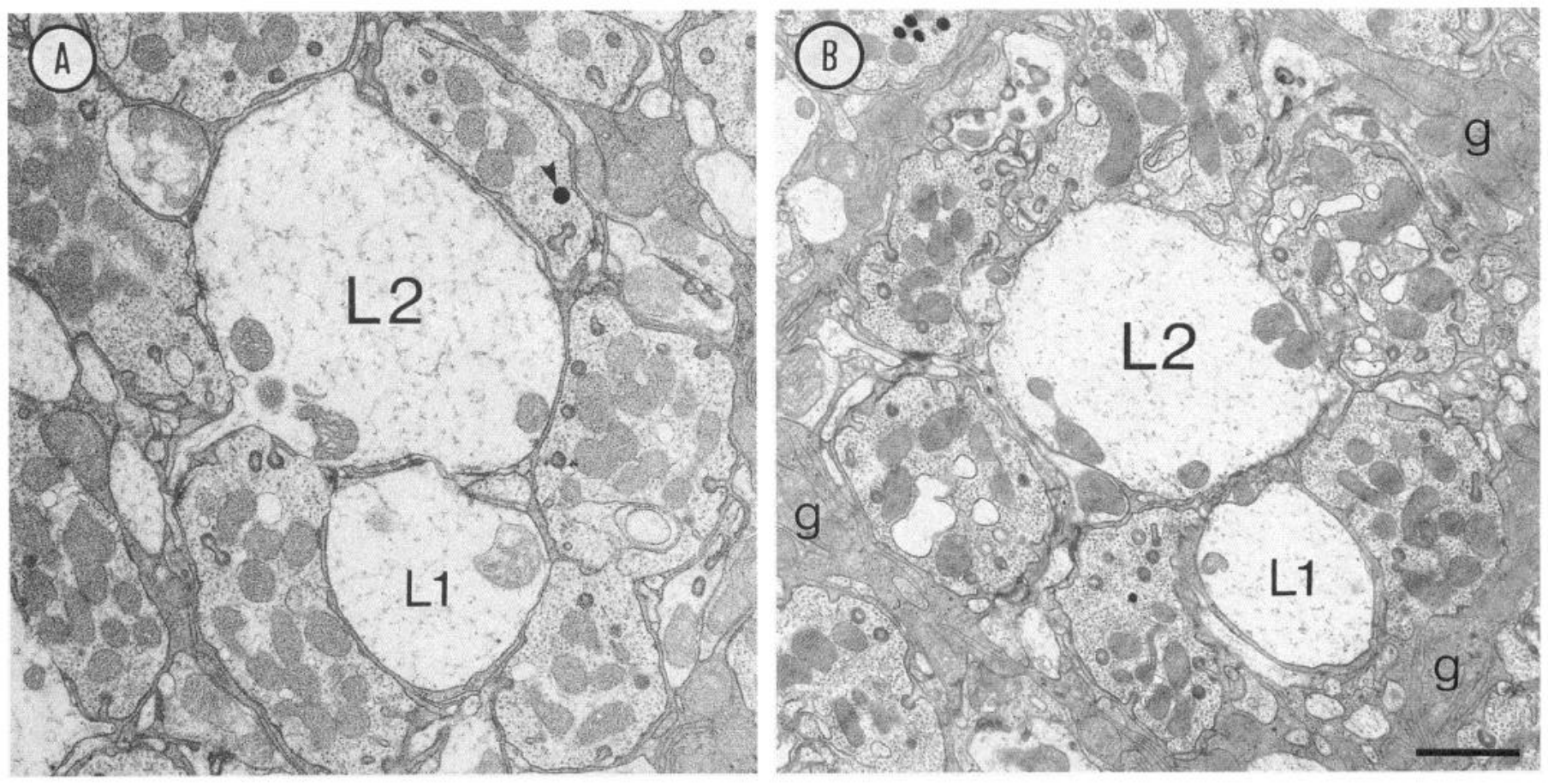

Figure 3. Electron micrographs of the lamina cartridge in female flies reared in LD. $A$, Fixed in the day, at 10:00 hr. $B$, Fixed at night at 22:00 hr. L1 and L2 are larger in the day $(A)$, while surrounding epithelial glial cells $(g)$ are larger in the night $(B)$. Typically, the receptor terminals have pigment granules (arrowhead in $A$ ). Magnification, $6280 \times$; scale bar, $2.0 \mu \mathrm{m}$.

larger than in males measured at 09:00 and 21:00 hr, and was statistically significant $(p<0.05)$. The difference in significance between males (group I) and females (group II) can be explained if cell sizes in males were measured on the night/day and day/ night transitions whereas in females they were measured one hour after the beginning of day and night, when the day/night differences in cell size were greater. Not only were day/night differences in L2 similar between males and females, but the absolute sizes were also similar, in males at 09:00 hr (group IA) the size for L2 was less than $1 \%$ different than in females at 10 : 00 (group IIA). At 21:00 hr (male flies) L2 was about 15\% larger, however, than it was in female flies at 22:00, and similar differences were seen in L1 for both 09:00 and 21:00 hr when compared with the corresponding values in females. None of these differences was statistically significant, however.

In turn, $\mathrm{L} 1$ at $10: 00 \mathrm{hr}\left(5.6 \pm 1.58 \mu \mathrm{m}^{2} \mathrm{SD}\right.$ at level $1 ; 3.3 \pm$ $0.85 \mu \mathrm{m}^{2} \mathrm{SD}$ at level 5) was similar in size to $\mathrm{Ll}$ at $22: 00 \mathrm{hr}$ $\left(5.6 \pm 1.82 \mu \mathrm{m}^{2} \mathrm{SD}\right.$ at level $1 ; 2.3 \pm 0.73 \mu \mathrm{m}^{2} \mathrm{SD}$ at level 5$)$ (Figs. $3 A, B, 6 B$ ). Only at distal levels of the lamina was L1 larger at 10:00. At level 4 it was 13\% larger and at level $531 \%$ larger during the day than during the night; only the difference at level 5 was statistically significant $(p<0.005)$. In both groups IIA and IIB there were no statistically significant differences between individual flies.

The results thus reveal a day/night rhythm of axonal size in L2 in both male and female flies. L1, on the other hand, did not show a clear rhythm of size changes, its size merely decreasing in the middle and at the end of night. L2 was always larger during the day, especially at the beginning of day, and was smaller during the night, especially in the middle of night. The largest day/night difference in the cross-sectional area of L2's axon was observed at proximal levels of the lamina (levels $1,2)$.
To examine whether changes in the girth of L1 and L2 may have been offset by changes in their lengths, so as to conserve cell volume, the lengths of both axons were also measured, as a pair, from longitudinal sections of the lamina examined during the day (group IA) and night (group IE). During the day, the axons were $8.5 \%$ longer $(54.5 \pm 4.39 \mu \mathrm{m} \mathrm{SD}, n=37)$ than during the night $(49.9 \pm 4.33 \mu \mathrm{m} \mathrm{SD}, n=70)$. This difference was statistically significant $(p=0.0001)$. Thus the day/night volumetric differences between the lamina monopolar cell axons were not offset by the length of L1 and L2, but were increased further.

\section{The effects of water deprivation}

Since a day/night osmotic cycle would provide an obvious explanation for a general increase in lamina cell sizes, flies were water deprived to examine the effects of osmotic shifts on the lamina cells. Water deprivation for $12 \mathrm{hr}$ (groups III) induced an increase in the sizes of L1 and L2's axons, which was, however, statistically significant only for group IIIA. After water deprivation (group III) L1's axon, as a mean of the cross-sectional area at five lamina depths, was $50 \%$ larger at 10:00 hr (group IIIA) and unchanged at 22:00 hr (group IIIB), while L2 was $29 \%$ larger at $10: 00 \mathrm{hr}$ and only $4.4 \%$ larger at $22: 00 \mathrm{hr}$, than the corresponding values in group II flies. Thus, only dehydration before the beginning of the day had a physiological effect, but a paradoxical one in increasing cell size.

Water deprivation also increased the day/night difference in cell sizes. After dehydration, both L1 and L2 were larger at the beginning of day (L1, $15.4 \pm 5.21 \mu \mathrm{m}^{2} \mathrm{SD}$ at level $1 ; 3.5 \pm$ $0.64 \mu \mathrm{m}^{2} \mathrm{SD}$ at level $5 ; \mathrm{L} 2,22.1 \pm 5.39 \mu \mathrm{m}^{2}$ SD at level $1 ; 3.4$ $\pm 1.02 \mu \mathrm{m}^{2} \mathrm{SD}$ at level 5) than at the beginning of night (L1, $5.7 \pm 1.78 \mu \mathrm{m}^{2} \mathrm{SD}$ at level $1 ; 2.5 \pm 1.20 \mu \mathrm{m}^{2} \mathrm{SD}$ at level 5 ; L2, $10.0 \pm 2.81 \mu \mathrm{m}^{2}$ SD at level $1 ; 2.33 \pm 0.80 \mu \mathrm{m}^{2}$ SD at level 


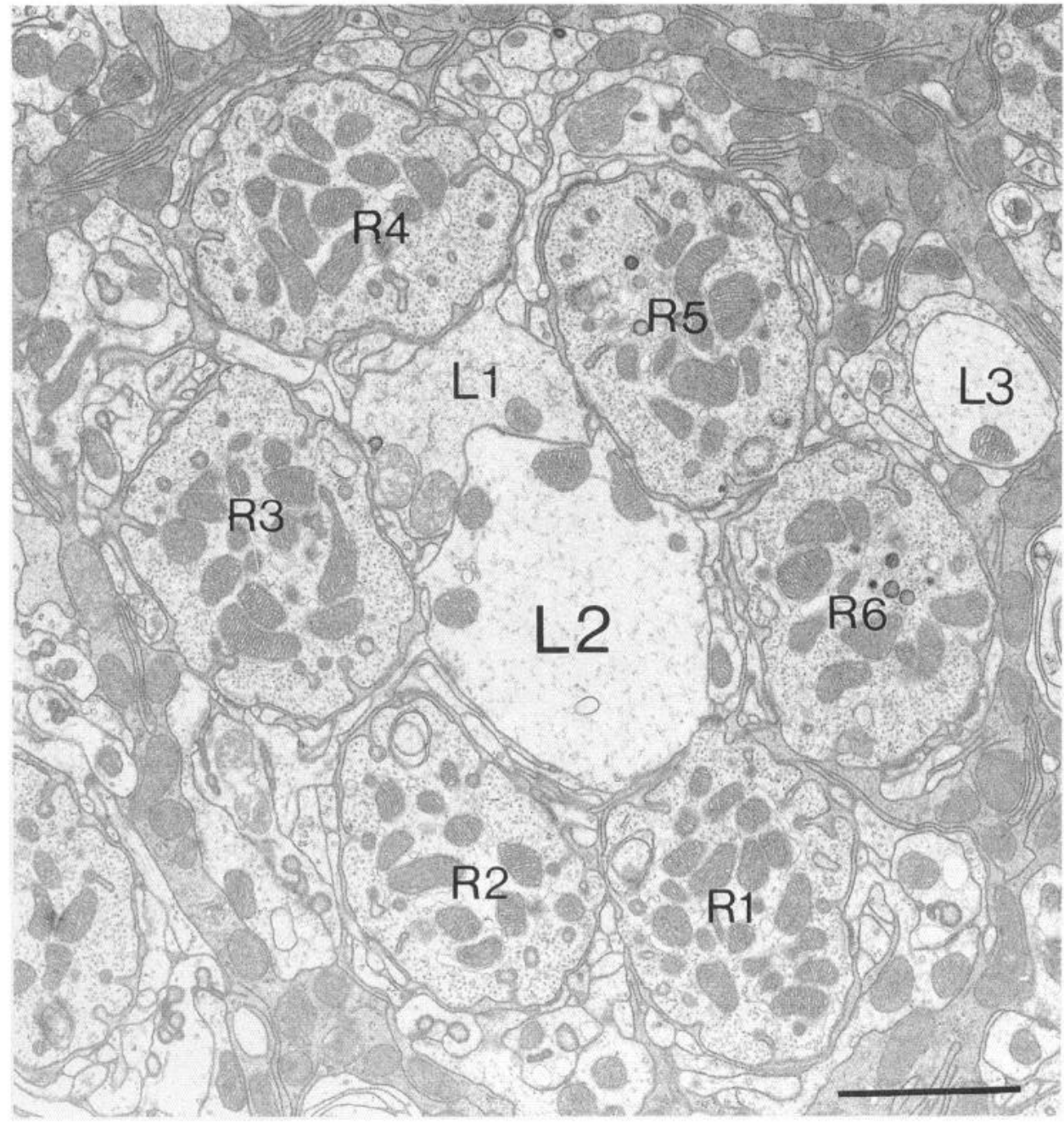

Figure 4. Electron micrograph of a lamina cartridge from a female fly reared in $\mathrm{LD}$ and dissected at night $(22: 00 \mathrm{hr})$. Representative of some cartridges in the night-fixed lamina, one of the monopolar cells is of smaller size, shrunken appearance and with cytoplasm that is more electron dense, than other cartridges in the lamina (cf. Fig. $3 B$ ). Defining positions of the terminals of $R I-$ $R 6$, the axon of $\mathrm{L} 3$, a third monopolar cell, lies between $R 5$ and R6. Magnification, $10,600 \times$; scale bar, $2.0 \mu \mathrm{m}$.
5) (Fig. $7 A, B$ ). L1 was larger at all lamina depths, between $63 \%$ (level 1 ) and $37 \%$ (level 5) larger in group IIIA than in group IIIB. L2 was likewise larger at all depths, between 55\% (level 1) and $31 \%$ (level 5) larger $1 \mathrm{hr}$ after light-on (group IIIA) than $1 \mathrm{hr}$ after light-off (group IIIB). The day/night differences in the sizes of L1 and L2 after dehydration were statistically significant only for L2 ( $p<0.01)$, however, and not at all for L1.

The difference in the amount of swelling in $\mathrm{L} 1$ and $\mathrm{L} 2$ induced by water deprivation, when that swelling was compared between the beginning of day and the beginning of night, was more pronounced than the swelling observed without water deprivation, in groups I and II. L1 was especially enlarged at 10:00 hr after water deprivation, whereas in groups I and II, the size of $\mathrm{Ll}$ at 10:00 hr was similar to its size at $22: 00 \mathrm{hr}$. Thus, dehydrating flies for $12 \mathrm{hr}$ magnified the day/night differences in the sizes of $\mathrm{L} 1$ and $\mathrm{L} 2$

In order to examine whether the day/night differences were of circadian origin, and if so to what extent, flies were also examined that had been held in constant conditions.

\section{$L 1$ and $L 2$ axon sizes in constant darkness}

Under constant darkness (DD) (group IV), L1 and L2 were both smaller than under day/night (LD) conditions (group II). At 10: $00 \mathrm{hr}$ (the fly's subjective day) L1 and L2 were both $39 \%$ smaller, while at 22:00 (subjective night) L1 was 39\% smaller and L2
$30 \%$ smaller than the corresponding LD values. These differences were all statistically significant $(p<0.05)$. At 10:00 hr, the cross-sectional area of L2 was $8.5 \pm 2.17 \mu \mathrm{m}^{2} \mathrm{SD}$ at level 1 to $2.2 \pm 0.88 \mu \mathrm{m}^{2} \mathrm{SD}$ at level 5 and $\mathrm{L} 1$ was $3.8 \pm 1.72 \mu \mathrm{m}^{2}$ $\mathrm{SD}$ at level 1 to $1.78 \pm 0.48 \mu \mathrm{m}^{2}$ SD at level 5 . At $22: 00 \mathrm{hr}$, the size of $\mathrm{L} 2$ was $5.8 \pm 1.36 \mu \mathrm{m}^{2} \mathrm{SD}$ at level $l$ to $1.8 \pm 0.52$ $\mu \mathrm{m}^{2} \mathrm{SD}$ at level 5 and $\mathrm{Ll}$ was $3.3 \pm 1.28 \mu \mathrm{m}^{2} \mathrm{SD}$ at level $l$ to $1.5 \pm 0.43 \mu \mathrm{m}^{2}$ SD at level 5 (Fig. $8 A, B$ ). The sizes of both cells were larger during the subjective day at $10: 00 \mathrm{hr}$ (group IVA) than during subjective night at $22: 00 \mathrm{hr}$ (group IVB) at all lamina depths, but only the differences in L2's size were statistically significant ( $p<0.05$ ). L2 was between $32 \%$ larger at level 1 and $17 \%$ larger at level 5 at the beginning of subjective day than at the beginning of subjective night. The differences between individual flies within groups IVA and IVB were not statistically significant.

\section{L1 and L2 axon sizes in constant light}

Under constant light (LL) conditions (group V), the size of L1 and L2 both increased with respect to their size in flies held under LD (group II). The respective increases at 10:00 $\mathrm{hr}$ were $50 \%$ and $21.8 \%$, and at $22: 00 \mathrm{hr}$ were $33 \%$ and $32 \%$. These differences were all statistically significant $(p<0.05)$. At 10:00 (group VA), the cross-sectional area of Ll's axon ranged from $13.1 \pm 4.48 \mu \mathrm{m}^{2} \mathrm{SD}$ (level 1) to $5.2 \pm 2.22 \mu \mathrm{m}^{2} \mathrm{SD}$ (level 5); 

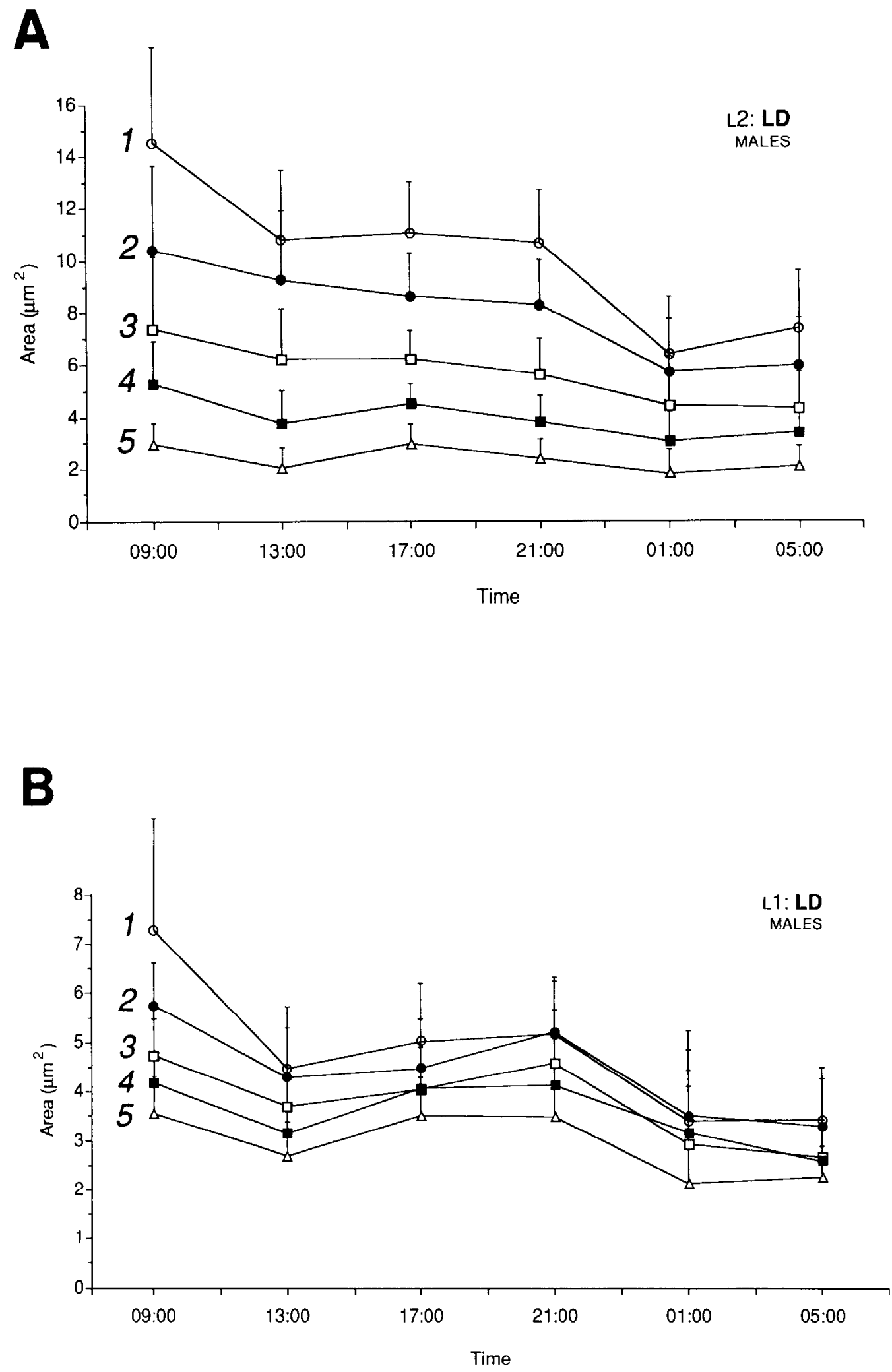

Figure 5. $A$ and $B$, Changes in the axonal cross-section areas of $\mathrm{L} 2(A)$ and $\mathrm{Ll}(B)$ at levels $1-5$ in the lamina measured every $4 \mathrm{hr}$ in $\mathrm{LD}$ in male flics. Mean $\pm \mathrm{SD}$.

that of $\mathrm{L} 2$ from $18.4 \pm 3.7 \mu \mathrm{m}^{2} \mathrm{SD}$ (level 1 ) to $5.7 \pm 1.93 \mu \mathrm{m}^{2}$ SD (level 5) (Fig. 9A,B). Within LL, a comparison of cell sizes during the subjective day and night indicated that $\mathrm{L} 1$ and L2 axons were both larger during the subjective day than during the subjective night. Their changes thus resembled those seen in DD. The axon of $L 2$ was larger at 10:00 hr than at 22:00 hr, by an increase ranging from $25 \%$ at level $l$ to $42 \%$ at level 3 , but $35 \%$ at level 5 . The difference between the subjective day 

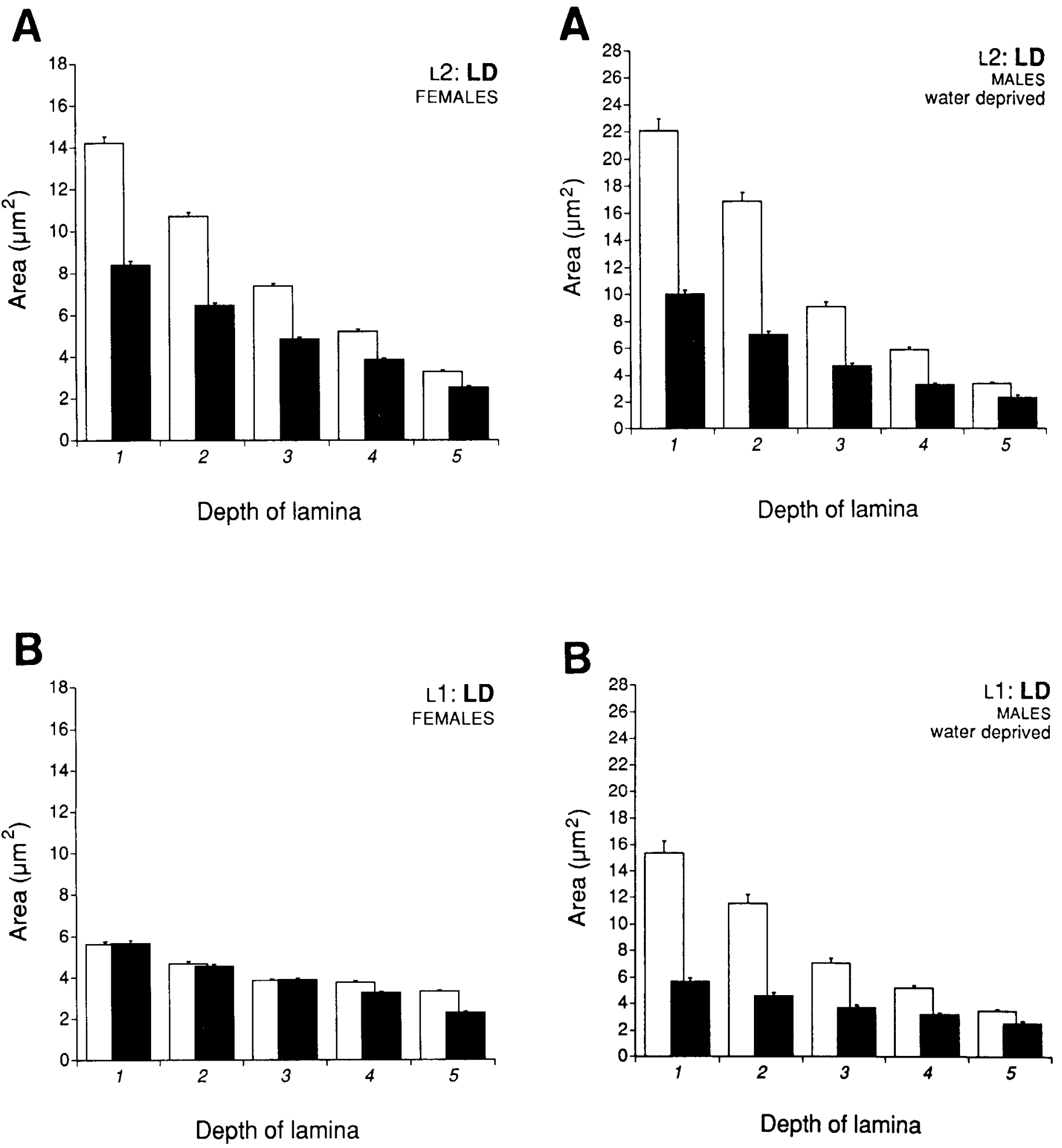

Figure 6. $A$ and $B$, Changes in the axonal cross areas of L2 $(A)$ and $\mathrm{Ll}(B)$ at levels $1-5$ in the lamina measured at 10:00 $\mathrm{hr}$ (open bars) and 22:00 $\mathrm{hr}$ (solid bars) in LD in female flies. Mean \pm SEM.

and subjective night in the mean axon size of $\mathrm{L} 2$ at the five lamina depths was statistically significant $(p<0.02)$. The axon size of $\mathrm{Ll}$ was also larger at 10:00 $\mathrm{hr}$ than at 22:00 (by 29\% at level $I$ to $39 \%$ at level 3 and $34 \%$ at level 5 ), but these differences were not statistically significant.

Figure 7. $A$ and $B$, Changes in the axonal cross areas of $\mathrm{L} 2(A)$ and $\mathrm{Ll}(B)$ at levels $1-5$ in the lamina measured after $12 \mathrm{hr}$ of water deprivation at 10:00 $\mathrm{hr}$ (open bars) and 22:00 $\mathrm{hr}$ (solid bars) in $\mathrm{LD}$ in male flies. Mean \pm SEM.

\section{$L 1$ and $L 2$ axon sizes in flies held in a reversed light regimen} In order to examine whether the circadian rhythm of cell size changes could be synchronized to a different LD cycle, finally flies were examined after reversing their day/night regime. Flies from group VIA were held first in LD for a total of $6 \mathrm{~d}$ and then 

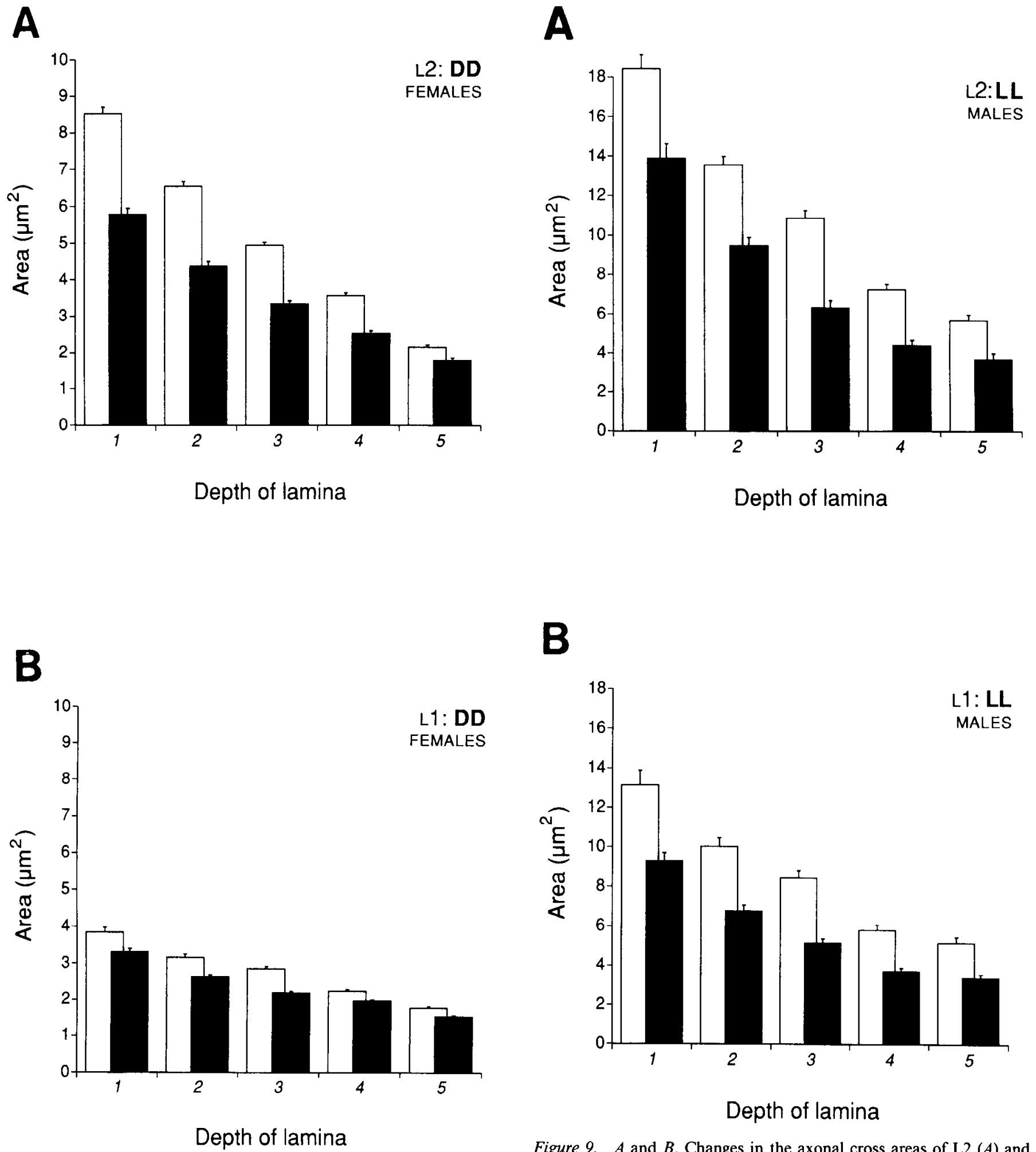

Figure 8. $A$ and $B$, Changes in the axonal cross areas of $\mathrm{L} 2(A)$ and $\mathrm{Ll}(B)$ at levels $l-5$ in the lamina measured at 10:00 $\mathrm{hr}$ (open bars) and 22:00 hr (solid bars) in constant darkness in female flies. Mean \pm SEM.

in the next day were brought into the reversed light regime (DL). Such flies were designated LDDL and, as a result, prior to fixation were exposed to darkness for one extra hour at the beginning of their seventh day (during the "new night"). This ex-

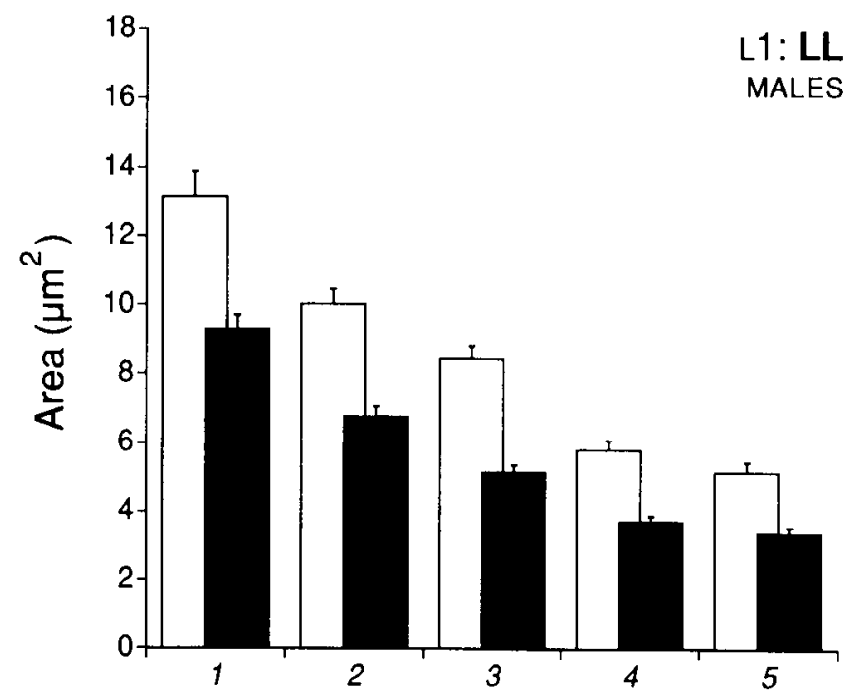

\section{Depth of lamina}

Figure 9. $A$ and $B$, Changes in the axonal cross areas of $\mathrm{L} 2(A)$ and $\mathrm{LI}(B)$ at levels $1-5$ in the lamina measured at 10:00 $\mathrm{hr}$ (open bars) and 22:00 hr (solid bars) in constant light in male flies. Mean \pm SEM.

tended the exposure to darkness received during the preceding night to $13 \mathrm{hr}$ (Fig. 1). Thus, axon sizes were measured in two groups of flies, one that received exposure to one extra hour of night (13 hr of darkness; group VIA) and one that received one additional hour of day after $24 \mathrm{hr}$ of darkness (group VIB). After one extra hour of night, the mean axonal cross-sectional area 

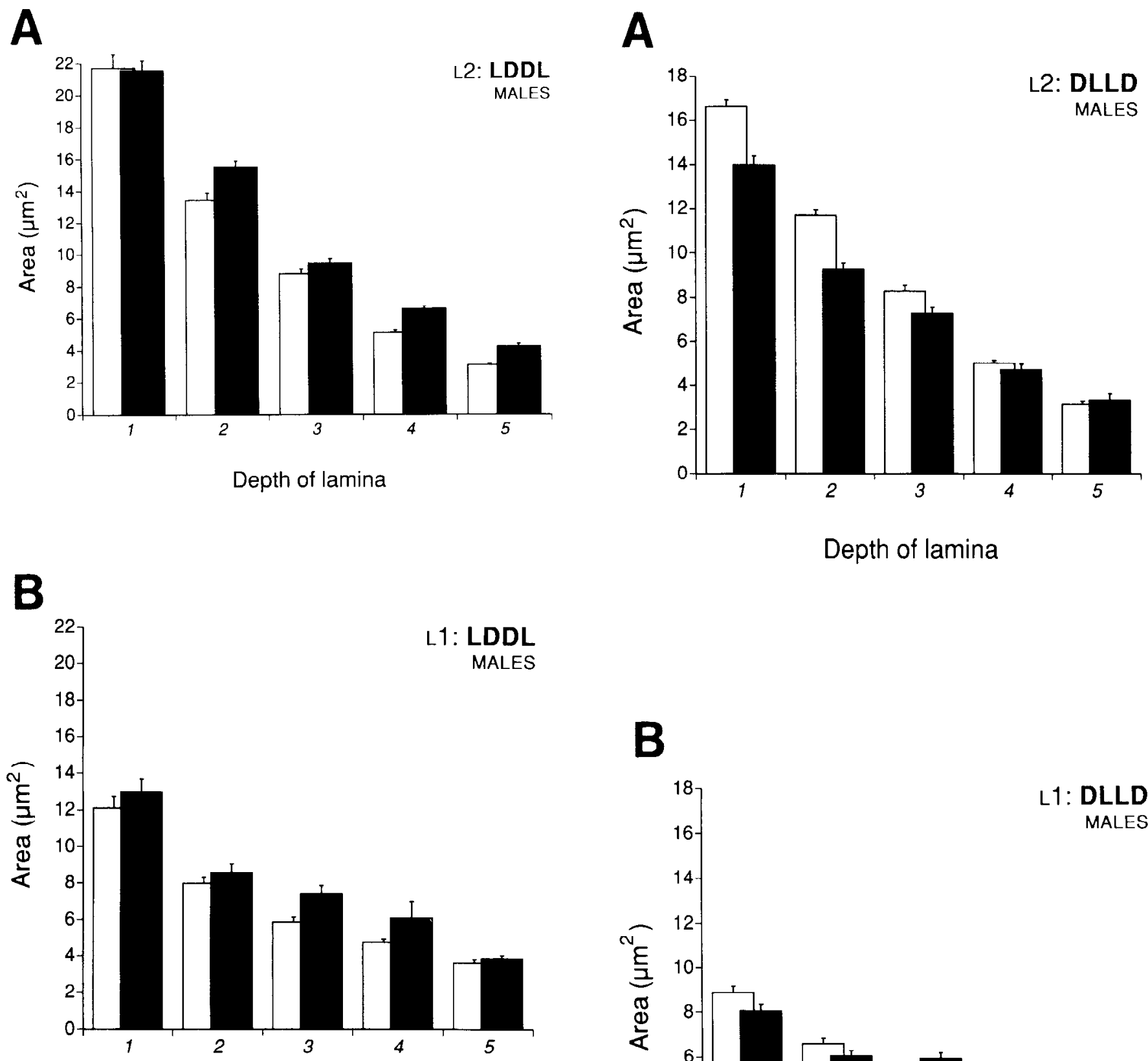

\section{Depth of lamina}

Figure 10. $A$ and $B$, Changes in the axonal cross areas of $\mathrm{L} 2(A)$ and $\mathrm{Ll}(B)$ at levels $1-5$ in the lamina measured at $10: 00 \mathrm{hr}$ ("new" night; open bars) and 22:00 $\mathrm{hr}$ ("new" day; solid bars) in male flies in the first day of a reversed-light regime. Mean \pm SEM.

of $\mathrm{L} 1$ was $7.6 \pm 1.92 \mu \mathrm{m}^{2} \mathrm{SD}$ and of $\mathrm{L} 2$ was $11.3 \pm 1.49 \mu \mathrm{m}^{2}$ $\mathrm{SD}$, in both cases similar to the sizes measured during the day in LD. The sizes of both L1 and L2, however, increased after one extra hour of day (group VIB), to $7.1 \pm 1.56 \mu \mathrm{m}^{2} \mathrm{SD}$ for $\mathrm{L} 1$ and to $10.1 \pm 1.82 \mu \mathrm{m}^{2} \mathrm{SD}$ for $\mathrm{I} .2$ (Fig. $10 A, B$ ). So, in spite of exchanging the time of day and night, L2 was larger at the beginning of the new night than at the beginning of the new day, according to the pattern established in LD $24 \mathrm{hr}$ earlier, although this difference was not statistically significant. The size of Ll was the same in the reversed light regime as in LD.

In turn, the next procedure of holding flies in the reversed

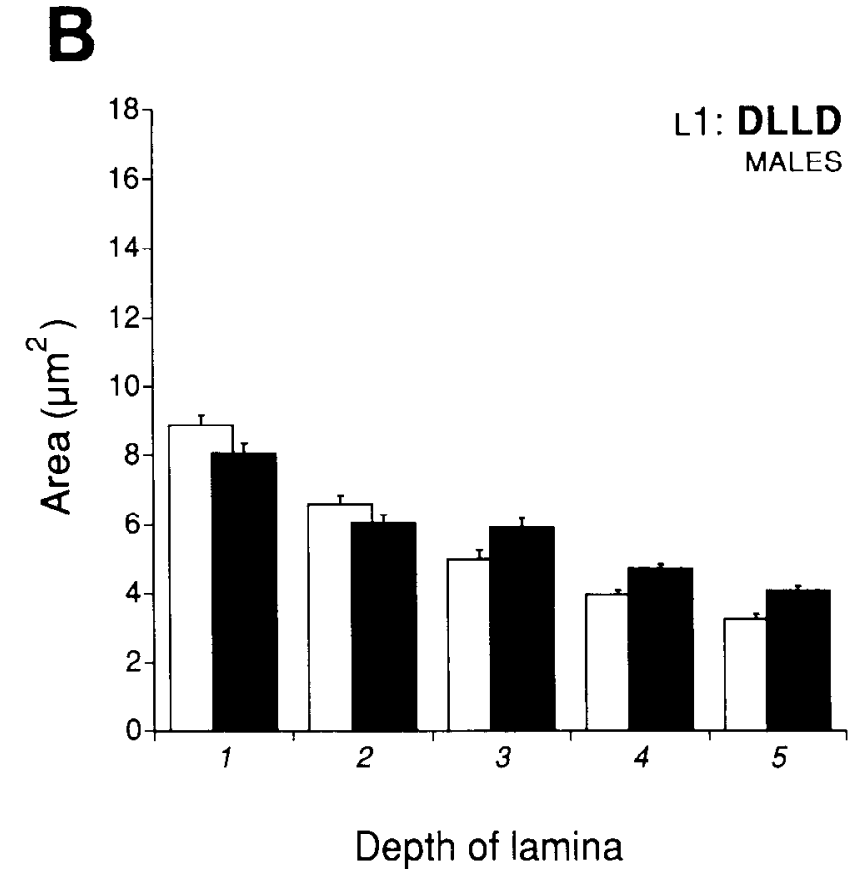

Figure 11. $A$ and $B$, Changes in the axonal cross areas of $\mathrm{L} 2(A)$ and $L 1(B)$ at levels $1-5$ in the lamina measured at 10:00 hr ("new" day; open bars) and 22:00 hr ("new" night; solid bars) in male flies in the first day of a LD regime after flies were held in a reversed-light regime. Mean \pm SEM.

light regime DL and $1 \mathrm{~d}$ in $\mathrm{LD}$, exposed flies to $13 \mathrm{hr}$ of the day (group VIIA) and $1 \mathrm{hr}$ of darkness after $24 \mathrm{hr}$ of light (group VIIB). In these new light conditions, $\mathrm{L} 1$ and $\mathrm{L} 2$ were similar in size in group VIIA $\left[5.7 \pm 0.44 \mu \mathrm{m}^{2} \mathrm{SD}(\mathrm{L} 1), 8.8 \pm 0.79 \mu \mathrm{m}^{2}\right.$ $\mathrm{SD}(\mathrm{L} 2)]$ as in group VIIB $\left[6.0 \pm 1.87 \mu \mathrm{m}^{2} \mathrm{SD}(\mathrm{L} 1)\right.$ and $8.0 \pm$ 
$\left.2.35 \mu \mathrm{m}^{2} \mathrm{SD}(\mathrm{I} .2)\right]$ (Fig. $11 A, B$ ). In this case, exchanging the times of light and darkness lengthened the light period to $13 \mathrm{hr}$ and the day/night rhythm of L2 size changes disappeared. The sizes of $\mathrm{L} 1$ and $\mathrm{L} 2$ at levels 1 and 2 in the lamina, however, were larger at the beginning of new day than at the beginning of new night. At the distal level of the lamina, on the contrary, the size of both was larger at the beginning of new night than at the beginning of new day. The two experiments, exposing flies either to LDDL (group VIA,B) or to DLLD (group VIIA,B) conditions, therefore indicate that exchanging the times of day and night can mask the daily rhythm of changes in the size of L2's axon. One hour of light during the night can increase the size of L1 and L2 but $1 \mathrm{hr}$ of darkness during the day cannot decrease its size. A period of light as long as $13 \mathrm{hr}$ can reverse the rhythm, but this process is slow, takes morc than onc cycle of a new regime and the difference in size is first visible only at the proximal level of the lamina.

\section{Discussion}

The results show clearly that $\mathrm{Ll}$ and $\mathrm{L} 2$, the two chief output interneurons of each cartridge in the fly's lamina, undergo a daily cycle of changes in the size of their axons, and that at least for $\mathrm{L} 2$ this process exhibits a circadian rhythm. The first significance to attach to these results is therefore that they offer evidence for the involvement of L2 in the circadian system of the fly's optic lobe, for which the location of the pacemaker is variously described (Helfrich, 1986; Ewer et al., 1992). While not necessarily a component of the pacemaker, L2 may nevertheless be driven by the pacemaker and thus, in turn, an effector of the pacemaker's rhythm.

In the housefly's visual system the number of synapses that transfer information between the photoreceptor terminals and lamina monopolar cells oscillates during the day and night and, in the case of the feedback synapses between L2 and the receptor terminals, their frequency has a circadian rhythm (Pyza and Meinertzhagen, 1991, 1993). Possibly related to these rhythms, or to rhythms that may also exist among the output synapses of L1 and L2's terminals in the medulla, the circadian rhythm in the cross-sectional size of $\mathrm{L} 2$, presented here, provides the second example of an endogenous rhythm detected in the fly's lamina. This rhythm is, moreover, much more readily assayed, from a single semithin section in each fly, than are the frequencies of synaptic profiles, and so provides an easy marker for the circadian state of the lamina. The rhythm of axonal size is, to our knowledge, the first example to suggest the existence of either a daily or circadian rhythm in the size of insect neurons, for which old observations that cells in the antennal lobe of the honey bee's brain are larger in diameter in the morning than in the evening (Hodge, 1892) possibly form another instance.

The changes in axon caliber of the two chief output cell classes in the housefly's lamina appear to differ during a $24 \mathrm{hr}$ period. L2 shows a clear day/night and circadian rhythm in its axonal cross-sectional area, with a peak not only during the day, but also during the subjective day in flies exposed to both DD and LL conditions. The changes are seen in female as well as in male flies. The changes in I 1 's cell size during a $24 \mathrm{hr}$ period of LD and under constant conditions are smaller than those of L 2 and are not significant. Moreover, oscillations in the size of $\mathrm{Ll}$ were not observed in group I flies exposed to LD conditions. We tentatively interpret this to mean that a possible rhythm in the cross-sectional area of $L 1$ is offset by a second effect, that due to the direct action of light or darkness. This interpretation is based on the observation that $\mathrm{Ll}$ is apparently more sensitive than L2 to long exposures to light. Under LL conditions, for example, $L 1$ was larger by about $41 \%$ than under LD, whereas L2 was larger by only $26 \%$ than it was under LD. A direct action of light and dark has been previously reported on the related visual system of Limulus, but in the retina (Chamberlain and Barlow, 1987).

This difference between $\mathrm{L} 1$ and $\mathrm{L} 2$ is hard to reconcile with the electrophysiological responses of these two cells. Changes in the axonal diameters of L1 and L2 have not been explicitly considered in the cable model that best fits the electrophysiological responses of these cells (van Hateren and Laughlin, 1990). Both monopolar cells are invariable partners at all input synapses (Nicol and Meinertzhagen, 1982), and so receive the same visual information from photorcceptor terminals. They exhibit responses to light flashes that are indiscriminable except to offaxis illumination (Laughlin and Osorio, 1989). The differences seen in this study between $\mathrm{Ll}$ and $\mathrm{L} 2$ now indicate that in response to longer periods of illumination the volumetric changes of these cells differ too. $\mathrm{L} 1$ responds more than $\mathrm{L} 2$ to the direct action of light exposure, while any possible circadian oscillation in its cross-sectional area might be masked by the volume increase due to light stimulation. L2 on the other hand maintains a circadian rhythm, which the reversed light regime shows can be synchronized by light. It is furthermore possible that L 2 could act as an output component of the circadian pacemaker, by driving circadian information through L2's input to the photoreceptor terminals, at feedback synapses.

The mechanism for changes in lamina monopolar cell volume changes is no more clear than their functional outcome. Cell volume changes have been seen in response to three types of stimulus: to light, which increases cell volume; to water deprivation, which also increases cell volume (with dehydration before the beginning of day having a stronger physiological effect than before the beginning of night); and, lastly, to an endogenous circadian rhythm.

Osmotic shifts might immediately be suggested as the proximate cause of a circadian rhythm, but apparently a generalized osmotic effect is not involved. Apart from the different size changes seen in $\mathrm{L} 1$ and $\mathrm{L} 2$, we have also made preliminary measurements of the cross-sections of terminals R1-R6 in LD and $\mathrm{DD}$, and these show no clear volume changes (E. Pyza, unpublished observations). Moreover, if the circadian rhythm were an osmotic phenomenon, it nevertheless survives the most obvious osmotic perturbation, dehydration. While it is true that water deprivation did result in a volume change in $\mathrm{L} 1$ and $\mathrm{L} 2$, this paradoxically was either an increase in cell size, or at least not a decrease. Possibly the cells undergo a regulatory volume increase in response to hypertonicity, as happens in the nephron (Montrose-Rafizadeh and Guggino, 1990). The mechanisms for such regulation involve ionic fluxes (Grinstein and Foskett, 1990), for which several described conductance channels exist in lamina monopolar cells, especially for potassium channels (Hardie and Weckström, 1990). Potassium is involved in volume regulation in the pigment epithelium cells of the frog's retina (Adorante and Miller, 1990), which probably shrink in response to a light-evoked increase of the volume of the subretinal space and a decrease in ionic concentration (Huang and Karwoski, 1992). It is also involved in cell volume changes amongst neuropil glial cells of the leech ganglion (Ballanyi et al., 1990). Light-evoked changes in the concentrations of calcium and sodium and in extracellular volume have also been detected in the insect retina, 
as part of the mechanism of light adaptation (Orkand et al., 1984; Ziegler and Walz, 1989; Sandler and Kirschfeld, 1991). Possibly they occur in the underlying lamina, too, where L1 and L2 predominantly hyperpolarize to light (Järvilehto and Zettler, 1971) through light-evoked chloride conductance increases (Zettler and Straka, 1987; Laughlin and Osorio, 1989).

Over and above these responses to light exposure, which plausibly result in ion fluxes, or even the responses to water deprivation, for which ion fluxes are possibly responsible but quite unproven, there still lies an entrained rhythm in cell volume, for which any mechanism may still be entertained. In other systems, ionic concentration changes are important regulators of circadian rhythms. In neurons of the circadian oscillator in the mollusc's eye, for example, they modify the free-running period of the circadian rhythm of electrical activity (Khalsa ct al., 1990; Ralph and Block, 1990), while in chick pineal cells ionic concentration changes that cause swelling or shrinkage of cells also regulate the phase of the circadian rhythm of melatonin synthesis (Zatz and Wang, 1991). While osmotic change and light activity both modulate cell size among L1 and L2 cells, they do not extinguish their circadian rhythm, which for the moment we therefore infer to be an independent process.

The magnitude of cell volume changes seen in L1 and L2 is largely that of the increase in axon cross-sectional area (up to $50 \%$ ), but is also augmented by a small increase in axon length. These changes in cell volume seem to be offset by a compensatory decrease in the volume of the surrounding epithelial glial cells (Fig. 3), but whether they are wholly accommodated within the lamina or whether the lamina itself also swells is not clear. Changes among the glial cell population provoke the same questions as those previously raiscd for $\mathrm{L} 1$ and $\mathrm{L} 2$, as to the reciprocal mechanism of volume regulation in these cells.

Volume changes in $\mathrm{L} 1$ and $\mathrm{L} 2$ provide an example not just of circadian rhythms in the fly's visual system, but also of plasticity amongst its neurons. Neuronal plasticity involving some form of morphological change has been widely reported in the adult nervous system. In response to acute injury or denervation, for example, neurons frequently exhibit sprouting (Raisman, 1969; Brown et al., 1981). A comparable reaction is also seen in the fly's lamina, during reactive synaptogenesis following deafferentation (Brandstätter et al., 1992). Plasticity is also seen in response to physiologically reversible challenges to the visual system, such as the effect of visual experience. Cells in the LGN, for example, shrink and are of smaller size if they are relatively deprived of their retinal inputs (Wiesel and Hubel, 1963; Kuppermann and Kasamatsu, 1983). Conversely, the caliber of L2's axon increases after ocular occlusion in the housefly (Kral and Meinertzhagen, 1989). More general stimuli such as water deprivation in animals can also result in various morphological changes among neurons, including volume changes. Swelling of cells after dehydration has been observed in the supraoptic nucleus among neurosecretory neurons of the rat's hypothalamus (Hatton and Walters, 1973). This finds a direct parallel in the present study on the housefly's lamina, where dehydration also increases the sizes of L1 and L2, even if significantly only when water deprivation occurs just before the time of the animal's peak activity, which for flies is during the day (Helfrich et al., 1985).

Finally, neuronal plasticity also occurs on a more predictable time scale, and embraces cyclical changes in the adult nervous system. Some examples are seasonal, as in hormone-induced changes in brain volume and neuron number in birds (Notte- bohm, 1981; Arnold, 1985) and in humans (Hofman and Swaab, 1992). Other examples are tidal, as in changes in the Golgi complex of cells in the neural ganglion and gland of adult tunicates (Georges, 1978). To date, however, there have been few reports of circadian oscillations involving either the volume or morphology of neurons, even though a diurnal rhythm is reported in the variation of magnocellular cell size in the rat's hypothalamus (Armstrong and Hatton, 1978) and of short photoreceptor cell size in the lamprey's retina (Hara et al., 1990). To these should now be added the subtle but repeatable size changes reported here among monopolar cells in the fly's lamina, and their circadian basis.

\section{References}

Adorante JS, Miller SS (1990) Potassium-dependent volume regulation in retinal pigment epithelium is mediated by $\mathrm{Na}, \mathrm{K}, \mathrm{Cl}$ cotransport. J Gen Physiol 96:1153-1176.

Armstrong WE, Hatton GI (1978) Morphological changes in the rat supraoptic and paraventricular nuclei during the diurnal cycle. Brain Res 157:407-413.

Amold AP (1985) Gonadal steroid-induced organization and reorganization of neural circuits involved in bird song. In: Synaptic plasticity (Cotman CW, ed). New York: Guilford.

Ballanyi K, Grafe P, Serve G, Schlue W-R (1990) Electrophysiological measurements of volume changes in leech neuropile glial cells. Glia 3:151-158.

Barlow RB jr, Chamberlain SC, Lehman HK (1989) Circadian rhythms in the invertebrate retina. In: Facets of vision (Stavenga DG, Hardie RC, eds), pp 257-280. Berlin: Springer.

Blest AD (1988) The turnover of phototransductive membrane in compound eyes and ocelli. Adv Insect Physiol 20:1-53.

Boschek CB (1971) On the fine structure of the peripheral retina and lamina ganglionaris of the fly, Musca domestica. Z Zellforsch Mikrosk Anat 118:369-409.

Braitenberg V (1967) Patterns of projection in the visual system of the fly. I. Retina-lamina projections. Exp Brain Res 3:271-298.

Braitenberg V, Hauser-Holschuh H (1972) Patterns of projection in the visual system of the fly. II. Quantitative aspects of second order neurons in relation to models of movement perception. Exp Brain Res 16:184-209.

Brandstätter JH, Shaw SR, Meinertzhagen IA (1992) Reactive synaptogenesis following degeneration of photoreceptor terminals in the fly's optic lobe: a quantitative electron microscopic study. Proc R Soc Lond [Biol] 247:1-7.

Brown MC, Holland RL, Hopkins WG (1981) Motor nerve sprouting. Annu Rev Neurosci 4:17-42.

Burkhardt W, Braitenberg V (1976) Some peculiar synaptic complexes in the first visual ganglion of the fly, Musca domestica. Cell Tissue Res 173:287-308.

Chamberlain SC, Barlow RB Jr (1987) Control of structural rhythms in the lateral eye of Limulus: interactions of natural lighting and circadian efferent activity. J Neurosci 7:2135-2144.

Ewer J, Frisch B, Hamblen-Coyle MJ, Rosbash M, Hall JC (1992) Expression of the period clock gene within different cell types in the brain of Drosophila adults and mosaic analysis of these cells' influence on circadian behavioral rhythms. J Neurosci 12:3321-3349.

Georges D (1978) Circadian rhythm in the neural gland of Ciona intestinalis. In: Comparative endocrinology (Gaillard PJ, Boer $\mathrm{HH}$, eds), pp 161-164. Amsterdam: Elsevier/North-Holland.

Grinstein S, Foskett JK (1990) Ionic mechanisms of cell volume regulation in leukocytes. Annu Rev Physiol 52:399-414.

Hara M, Yoshida M, Tonosaki A (1990) Fine structural and volumetric changes of lamprcy photoreceptor cells during light and dark periods. Cell Tissue Res 259:33-41.

Hardie RC, Weckström M (1990) Three classes of potassium channels in large monopolar cells of the blowfly Calliphora vicina. J Comp Physiol [A] 167:723-736.

Hateren JH van, Laughlin SB (1990) Membrane parameters, signal transmission, and the design of a graded potential neuron. J Comp Physiol [A] 166:437-448. 
Hatton GI, Walters JK (1973) Induced multiple nucleoli, nucleolar margination, and cell size changes in supraoptic neurons during dehydration and rehydration in the rat. Brain Res 59:137-154.

Helfrich C (1986) Role of the optic lobes in the regulation of the locomotor activity rhythm of Drosophila melanogaster: behavioral analysis of neural mutants. $J$ Neurogenet 3:321-343.

Helfrich C, Cymborowski B, Engelmann W (1985) Circadian activity rhythm of the house fly continues after optic tract severance and lobectomy. Chronobiol Int 2:19-32.

Hodge CF (1892) A microscopical study of changes due to functional activity in nerve cells. J Morphol 7:95-168.

Hofman MA, Swaab DF (1992) The human hypothalamus: comparative morphometry and photoperiodic influences. Prog Brain Res 93: 133-149.

Huang B, Karwoski CJ (1992) Light-evoked expansion of subretinal space volume in the retina of the frog. J Neurosci 12:4243-4252.

Järvilehto M, Zettler F (1971) Localized intracellular potentials from pre- and postsynaptic components in the external plexiform layer of an insect retina. Z Vergl Physiol 75:422-440.

Khalsa SBS, Ralph MR, Block GD (1990) Chloride conductance contributes to period determination of a neuronal circadian pacemaker. Brain Res 520:166-169.

Kral K, Mcincrtzhagen IA (1989) Anatomical plasticity of synapses in the lamina of the optic lobe of the fly. Philos Trans R Soc Lond [Biol] 323:155-183.

Kuppermann BD, Kasamatsu T (1983) Changes in geniculate cell size following brief monocular blockade of retinal activity in kittens. Nature 306:465-468.

Laughlin SB, Osorio D (1989) Mechanisms for neural signal enhancement in the blowfly compound eye. J Exp Biol 144:113-146.

Montrose-Rafizadeh C, Guggino W B (1990) Cell volume regulation in the nephron. Annu Rev Physiol 52:761-772.

Nicol D, Meinertzhagen IA (1982) An analysis of the number and composition of the synaptic populations formed by photoreceptors of the fly. J Comp Neurol 207:29-44.

Nottebohm F (1981) A brain for all seasons: cyclical anatomical changes in song control nuclei of the canary brain. Science 214:1368-1370.

Orkand RK, Dietzel I, Coles JA (1984) Light-induced changes in extracellular volume in the retina of the drone, Apis mellifera. Neurosci Lett 45:273-278.

Pyza E, Meinertzhagen IA (1991) The numbers of photoreceptor synapses in the fly's optic lamina reveal day/night (circadian?) changes. Soc Neurosci Abstr 17:216.

Pyza E, Meinertzhagen IA (1992) Day/night and circadian rhythms among cells of the lamina in the housefly's optic lobe. Soc Neurosci Abstr 18:39.
Pyza E, Meinertzhagen IA (1993) Daily and circadian rhythms of synaptic frequency in the first visual neuropile of the housefly's ( $\mathrm{Mus}$ ca domestica L.) optic lobe. Proc R Soc Lond [Biol] 254:97-105.

Raisman G (1969) Neuronal plasticity in the septal nuclei of the adult rat. Brain Res 14:25-48.

Ralph MR, Block GD (1990) Circadian and light-induced conductance changes in putative pacemaker cells of Bulla gouldiana. J Comp Physiol [A] 166:589-595.

Remé CE, Wirz-Justice A, Terman M (1991) The visual input stage of the mammalian circadian pacemaking system. I. Is there a clock in the mammalian eye? J Biol Rhythms 6:5-29.

Rybak J, Meinertzhagen IA (1990) Experience-dependent changes in the sizes and frequencies of photoreceptor synapses in the fly's optic lamina. In: Proceedings of the 18th Göttingen neurobiology meeting, brain-perception-cognition (Elsner N, Roth G, eds), p 196. Stuttgart: Thieme.

Sandler C, Kirschfeld K (1991) Light-induced extracellular calcium and sodium concentration changes in the retina of Calliphora: involvement in the mechanism of light adaptation. J Comp Physiol [A] 169:299-311.

Stark WS, Sapp R, Schilly D (1988) Rhabdomere turnover and rhodopsin cycle: maintenance of retinula cells in Drosophila melanogaster. J Ncurocytol 17:499-509.

Strausfeld NJ, Campos-Ortega JA (1977) Vision in insects: pathways possibly underlying neural adaptation and lateral inhibition. Science 195:894-897.

Trujillo-Cenóz O (1965) Some aspects of the structural organization of the intermediate retina of dipterans. J Ultrastruct Res 13:1-33.

White MP, Hock PA (1992) Effects of continuous darkness on ERG correlates of disc shedding in rabbit retina. Exp Eye Res 54:173-180.

Wiesel TN, Hubel DH (1963) Effects of visual deprivation on morphology and physiology of cells in the cat's lateral geniculate body. J Neurophysiol 26:978-993.

Williams DS (1982) Rhabdom size and photoreceptor membrane turnover in a muscoid fly. Cell Tissue Res 226:629-639.

Wills SA, Page TL, Colwell CS (1985) Circadian rhythms in the electroretinogram of the cockroach. J Biol Rhythms 1:25-37.

Zatz M, Wang H-M (1991) Low salt mimics effects of dark pulses on circadian pacemaker in cultured chick pineal cells. Am J Physiol 261(Regulatory Integrative Comp Physiol 30):R1424-R1430.

Zettler F, Straka H (1987) Synaptic chloride channels generating hyperpolarizing on-responses in monopolar neurones of the blowfly visual system. J Exp Biol 131:435-438.

Ziegler A, Walz B (1989) Analysis of extracellular calcium and volume changes in the compound eye of the honeybee drone, Apis mellifera. J Comp Physiol [A] 165:697-709. 